\title{
REMEDIOS OFTÁLMICOS EN LA MATERIA MÉDICA DE DIOSCÓRIDES (II)
}

\author{
LÓPEZ DE LETONA C ${ }^{1}$
}

El segundo libro de la obra que estamos considerando lleva por título: «Productos obtenidos de los animales, la leche, la enjundia, las legumbres y las hortalizas, añadiendo todas aquellas hierbas ácidas al gusto».

Antes de entrar en materia debemos señalar que el vocablo enjundia debe referirse a las grasas de origen animal y sobre todo a la manteca de cerdo. Las hierbas ácidas al gusto deben ser determinadas especies botánicas, poco frecuentes a las que nos referiremos después.

En este libro hemos localizado hasta treinta y un especímenes curativos, es por ello el más extenso de cuantos integran nuestra obra.

Comenzando por los animales se fija al comenzar en los pequeños moluscos como los mejillones (Mítulos), igualmente los caracoles, la víbora y el alacrán marino.

En cuanto a los primeros afirma que si se lavan «Como se lava el plomo» pueden resultar útiles «En las medicinas que se hacen para los ojos» porque adelgazan los párpados engrosados y resuelven «las nubes y todas las otras cosas que nublan la vista».

La ceniza de los caracoles quemados mezclada con miel, es capaz de deshacer las cicatrices que deforman la vista al tiempo que la fortifica.

El alacrán marino es un pez que no tiene nada que ver con el alacrán terrestre, si no es porque posee unas espinas muy venenosas. Su hiel puede resultar útil para curar las cataratas $« \mathrm{Y}$ otras flaquezas de la vista».

Caso parecido es de las víboras cuya carne cocida primero e ingerida después agudiza la vista. Es conveniente desollar primero al animal y posteriormente cortarle la cabeza y la cola.

En cuanto a los alimentos se refiere a huevos, leche y miel. La yema de los primeros asada y mezclada con azafrán y aceite es útil para los dolores oculares, la clara batida con incienso y dispuesta sobre la frente del enfermo es capaz de solucionar los procesos inflamatorios de origen oftalmológico.

La leche de mujer también unida al incienso puede instilarse en los ojos «afectados por algún golpe sangriento», recordemos que en algún artículo anterior nuestro ya nos henos referido a este producto como agente curativo.

Por su parte la miel: «Resuelve todos los impedimentos que ofuscan y obscurecen la vista».

Las grasas animales es decir la manteca de cerdo (Enjundia) son útiles por medio de su hollín, para ello se debe calentar la manteca en un «Vaso con aberturas por arriba y por abajo», una vez obtenido el producto es útil para las medicinas oculares porque posee propiedades desecativas «Y estipídicas», el primer término acaso lo haga útil en los casos de lagrimeo.

Posteriormente se refiere a las legumbres y en concreto a las habas y lentejas.

El harina de las primeras se debe mezclar con rosas, incienso y la clara de un huevo para «Reprimir los ojos salidos afuera y las hinchazones que ellos engendran». Si se bate el harina con vino solucionará las cataratas y «Socorrerán los ojos aporreados».

Finalmente si en vez de el harina se mascasen las habas sin hollejos el producto resultante se podría aplicar a la frente a fin de solventar los humores que suelen destilar los ojos.

Las lentejas mezcladas con pulpa de membrillo, aceite rosado y meliloto «Curan las inflamaciones de los ojos».

En cuanto a hortalizas cita entre otras las endivias, pero habla también de la calabaza, cebollas y lechugas, también el puerro cabezudo (que curiosamente y juntamente con el ajo masticado disminuye la vista) y el pepino doméstico del que indica que si

\footnotetext{
1 IOBA. Valladolid. España..

E-mail: berta@ioba.med.uva.es
} 
se ralla una de sus variantes (la llamada badea) y se aplica a la frente los humores «Que suelen producir los ojos» quedarían reprimidos.

El zumo de la cebolla mezclado con miel es útil «Contra la catarata que comienza a congelarse» así como contra las nubes oculares.

¿Qué quiere decir Dioscórides exactamente con el término «Catarata que comienza a congelarse»? pudiera darse el caso de que ya por entonces tuviesen nociones de lo que significaba el cristalino opacificado o bien las cataratas ya maduradas, pero la verdad es que no hemos llegado a tener noticias a este respecto.

En cuando a las «hierbas ácidas al gusto»a las que nos referíamos antes vamos a citar algunas de ellas. De comienzo la dragontea maior cuyo zumo es útil en las medicinas de los ojos «Por que resuelven las nubes que ofuscan la vista».

O el jengibre cuya raíz soluciona los impedimentos que ofuscan la visión. También podemos incluir el ciclamino y aquí vuelve a referirse a la catarata porque si esta hierba se mezcla con miel y se untan los ojos con la mezcla se pueden clarificar las opacidades cristalinas.

La celidonia por su parte debe utilizarse cociendo su zumo y mezclándolo con miel en un vaso de cobre, debe hacerse sobre una lumbre alimentada con carbón. El producto obtenido clarifica notoriamente la visión.

El aloe producto conocido desde la antigüedad y utilizada en algunas ocasiones como tónico dermatológico disuelve «Las uñas que suelen sobrevenir en los ojos».

También el abrótano (utilizado algunas veces para fortalecer el cuero cabelludo) puede mezclarse con membrillo cocido con miga de pan para mitigar las inflamaciones oculares.

Es posible que con este último término que hemos encontrado con frecuencia en la traducción de Laguna se esté refiriendo a los procesos inflamatorios que afectan sobre todo a la conjuntiva. 